and, if he would favor me with them, I should feel much flattered, - firstly, his estimate, from the census results, of the number of persons of the age of fifteen and upwards, resident in the British Islands, whose statements he would consider prima facie entitled to full credence (to guide him I may remark that I see no reason why the number should not be from ten to twenty millions); secondly, his estimate of the probability that one of these persons, taken at random, would not be above amusing himself or herself at the expense of a society so eminent as that of which Mr. Gurney is the honorary and honored secretary. These numbers will come into my discussion, and I should much rather have them from an authority conversant with the subject than attempt to guess at them myself.

Simon Newcomb.

\section{Change in the color of the eye.}

The experience of Mr. T. F. McCurdy (p. 452) is, I imagine, a not uncommon one. It certainly finds illustration in my own family and in myself; the iris, which was quite black in childhood, having for many years visibly lightened, until it is more correctly described as gray, with shades of hazel. The fading-out of black eyes with age is a matter of common observation; and the change, judging from the facts within my own knowledge, is more apt to occur where the individual takes after a grandparent who had the dark eye, and where the immediate parents had blue or gray.

C. V. RILEY.

Washington, D.C.

\section{Specimens illustrating Lehmann's 'Origin of the crystalline schists.'}

It may not be uninteresting to the geological readers of Science to know that the writer has recently received, through the kindness of Professor Johannes Lehmann of the University of Breslau, a very valuable suite of rock specimens illustrative of the latter's new and important work on the origin of the crystalline schists, noticed in Science, No. \$6, p. 327, and in the American journal of science for November, 1884, p. 392. These specimens are sixty-three in number, and were collected, partly by Professor Lelımann himself, and partly under his immediate supervision, in the granulite area of Saxony, and in those parts of Bavaria which he has made the subject of his special study. They exhibit in an excellent manner nearly all those phenomena ascribed by the author of the above memoir to metamorphism by pressure, especially, however, the changes which certain massive pyroxene rocks of Saxony have undergone in becoming hornblendic schists exactly analogous to similar alterations traced by the present writer in the rocks near Baltimore.

To all students of metamorphism and of structural geology in highly crystalline regions, this work must be of absorbing interest as undoubtedly the most advanced of its kind; and, in spite of its superb atlas of most satisfactory photographic illustrations, its readers may be glad to know that this suite of original specimens is in the petrographical laboratory of the Johns Hopkins university, where it will always be accessible to such persons as may be interested in examining it.

Baltimore, Nov. 25.

\section{Bot-flies in a turtle.}

Some days ago Prof. $\mathrm{T}$. Robinson of Howard university called my attention to a box-turtle (Cistudo carolina) which had in the muscles on either side of the neck about thirteen large bot-fly larvae. The turtle was alive, but evidently suffered inconvenience from the intruders which had taken up their abode at a point from which they could not be dislodged by claw or beak. They were removed with forceps, and sent to Mr. Howard of the agricultural bureau, who informed me that they belonged to the family Oestridae, and to a genus probably undescribed. He also brought to my attention an exactly parallel case reported in the American naturalist (xvi. 598) about two years ago by Prof. A. S. Packard.

Frederick W. Truk.

U. S. national museum, Washington,

Nov. 24.

On the function of the serrated appendages of the throat of Amia.

Through the kindness of Prof. B. G. Wilder I have at present two living specimens of Amia which $I$ propose to employ shortly in a comparative study of the brains of American ganoids.

My attention was first attracted to the serrated appendages of the throat by Professor Wilder's own note upon the subject, published in the Proc. Amer. assoc., 1876 , and more recently by a reference to the same structures in one of Sagemehl's admirable contributions to the anatomy of fishes (Morph. jahrb. x. 63). Sagemehl concludes, from the examination of alcoholic specimens, that these 'flagella' are, during life, in constant motion, and thus help to renew the water in the gill-cavity. Such is by no means the case. The 'flagella' are attached by their bases to the lateral aspects of the sterno-hyoid muscles (hyopectorales of McMurrich), the chief function of which is to enlarge the cavity of the mouth. When these muscles are at rest, the flagella lie flat along their surfaces: when they contract, the cavity of the mouth is enlarged, the flagella erected, and the gillcovers pushed outwards. At the suggestion of my assistant, Mr. A. B. Macallum, we stimulated the proximal part of the muscle with the result of a perfect demonstration of the above facts. The flagella thus help to replace functionally the absent dilatator muscles of the gill-covers. A strip of condensed tissue occupies a precisely similar position on the hyopectoral muscle of Amiurus, perhaps a rudiment of similar organs possessed by the ancestors of the siluroids before the differentiation of the dilatator muscles of the operculum.

My specimens of Amia, after being in captivity for some time, became very sluggish, and hardly any movements of respiration could be detected. After the fish had been removed for a little out of the water, however, and then returned to it, the movements were sufficiently active to disclose the following facts: -

During the enlargement and filling of the cavity of the mouth, the posterior flexible (and muscular) border of the gill-cover is tightly applied to the soft parts behind the gill-opening. When the mouthcavity is quite full, the mouth closes, the muscular border of the gill-cover releases its sucker-like hold of the soft parts, and the water is driven out by the contraction of the walls of the mouth-cavity.

Professor Wilder's account of the structure of the serrated appendages is so complete as to render any further reference to this subject unnecessary.

\section{R. RAMSAY WRIGHT.}

University college, Toronto, Nov. 27. 